final upper limit $1 \mathrm{mK}$ for a quadrupole term. Fabbri et al. are similarly cautious. They consider their effect, 4.5 standard deviations from zero, to be only 'suggestive' of a quadrupole anisotropy. Only the Princeton group is convinced that they have been able to take all systematic errors into account.

If their quadrupole term is verified, then the Princeton group will deserve credit for their unambiguous announcement of its discovery. But $I$ think it is premature to accept the effect as proven. Caution is called for, in part because the experiments are difficult, in part because of the discrepancies between the existing experiments, and in part because the results are close to those expected. Fortunately we may not have long to wait for verification. The Princeton group has already flown in their balloon gondola a maser receiver with considerably improved sensitivity, and the Berkeley group is about to fly a $90 \mathrm{GHz}$ cryogenic system. The frequency behaviour of the quadrupole term will clearly identify it as cosmic background or as galactic interference, and in a few years we should obtain a detailed map of the $3 \mathrm{~K}$ signal, including higher harmonics, from NASA's Cosmic Background Explorer satellite (COBE). The coverage and sensitivity of $\mathrm{COBE}$ are likely to give cosmologists a whole handful of new facts to inspire and constrain their theories.

1. Smoot, G.F., Gorenstein, M.V. \& Muller, R.A. Phys. Rev. Lett. 39, 898 (1977).

2. Cheng, E.S., Saulson, P.R., Wilkinson, D.T. \& Corey, B.E. Astrophys. J. Lett. 232, L139 (1979).

3. Fabbri, R., Guidi, I., Melchiorri, F. \& Natale, V. Phys. Rev. Lett, 44, 1563 (1980).

4. Boughn, S.P., Cheng, E.S. \& Wilkinson, D.T. Astrophys. J. Lett. 243, L113 (1980).

5. Alpher, R.A., Bethe, H.A. \& Gamow, G. Phys. Rev. 73 803 (1948); Alpher, R.A. \& Herman, R.C. Rev. Mod. Phys. 22, 153 (1950) and earlier references Mod. Phys.
therein.

6. Dicke, R.H., Peebles, P.J.E., Roll, P.G. \& Wilkinson, D.T. Astrophys. J. 142, 414 (1965).

7. Penzias, A.A. \& Wilson, M.L. Astrophys. J. 142, 419 (1965).

8. Peebles, P.J.E. Astrophys. J. Lett. 243, L.119(1981).

9. Silk, J. \& Wilson, M.L. Astrophys. J. Lett. 244, L37 (1981).

10. Smoot, G.F. \& Lubin, P.M. Astrophys. J. Lett. 234, L83 (1979).

\title{
Sexual differentiation of the brain
}

\section{from Bruce $S$. McEwen}

TESTOSTERONE acts during a limited period of perinatal development in male mammals to influence permanently the development of reproductive behaviour and neuroendocrine function, as well as to promote development of the reproductive tract. Although for some years the brain, and not the pituitary, has been presumed to be a site of testosterone action during development, it is only recently that there has been significant progress in understanding what actually happens to the brain during sexual differentiation.

Neuroanatomical studies have led the way, beginning with the first observation of sex differences in the sizes of nucleoli and cell nuclei in brains of gonadally intact $^{1}$ and hormone-treated ${ }^{2}$ adult rodents and primates ${ }^{3}$. This initial work left open the question of whether hormone action during early development or during adult life was responsible for the morphological features. This question was answered in rat by the electron microscopic studies of Raisman and Field ${ }^{4}$, which revealed that a sex difference in patterns of synaptic organization in the preoptic area of the adult rat depends, at least in part, on exposure to testosterone immediately after birth. Since then, studies at the light and electron microscopic levels have revealed sex differences in central nervous system morphology in songbirds ${ }^{5,6}$ and rodents ${ }^{7-12}$. Among the more notable features of some of these sex differences is their occurrence in neural pathways and brain regions related to sexually dimorphic and hormone-dependent neural events such as song in birds $s^{5,6}$, penile movement ${ }^{11}$ and gonadotropin secretion ${ }^{10}$ in rats.

How do these sex differences arise during the critical period of early perinatal neural development in mammals and birds? One mechanism

Burce S. McEwen is at the Rockefeller University, New York. being investigated is testosteronestimulated neurite growth, which has been demonstrated in organ culture ${ }^{13}$ where it appears to emanate from developing neurones that contain hormone receptors ${ }^{14}$. According to current ideas regarding the sequence of cellular events in neural development ${ }^{15}$, neurite growth stimulated by gonadal hormones might be a sufficient condition for the production of differences in cell number and cell size as well as in the patterns of synaptic connections that are the major features of the sex differences described in the adult brain ${ }^{4-12}$. In spite of the appeal of such a scheme, it would be premature to overlook possible testosterone effects on other aspects of neural development, including the reinitiation of cell division or the promotion of cell death, and the production of substances, like nerve growth factor, which stabilize synaptic contacts. Furthermore, testosterone might alter the neurotransmitter phenotype of developing neurones - a possibility suggested by the actions of glucocorticoids on neurotransmitter type in developing sympathetic ganglia ${ }^{16,17}$.

Hormonal stimulation of sexual differentiation occurs at a stage of neuronal development when considerable cellular differentiation has already occurred - oestrogen ${ }^{18,19}$ and androgen ${ }^{20,21}$ receptors and enzymes involved in testosterone metabolism to oestradiol 22 and 5- $\alpha$-dihydrotestosterone ${ }^{23}$ have already been laid down in certain neural cells. These enable particular neurones to respond to the hormonal signal, and it is known that both androgens and oestrogens arising from testosterone participate in sexual differentiation ${ }^{24}$, albeit in differing degrees depending on the species ${ }^{25}$. Oestrogen and androgen receptors are already present in the hypothalamic area of female rodents in the last trimester of gestation ${ }^{19,20}$ from around the time of final cell division ${ }^{26}$. There are also indications that oestrogen receptor levels in male and female rat brain start to increase shortly before birth ${ }^{18}$ and that androgen receptor levels increase from one week after birth ${ }^{21,27}$. There are at present no indications for rat or mouse that, at these early ages, sex differences exist in levels of neural oestrogen and androgen receptors. Rather, it is the sex differences in testosterone levels in late fetal life $\mathrm{e}^{28}$ resulting in differential occupation of receptor sites in male and female brains ${ }^{29,30}$ which provide the bias leading to sex differences.

Uncovering the factors, hormonal or otherwise, which govern the first appearance and subsequent perinatal increases of oestrogen and androgen receptors and testosterone-metabolizing enzymes in both male and female brains represents a major challenge for our further understanding of the origins of brain sex differences.

. Pfaff, D.W. J. Endocr. 36, 415 (1966)

Dörner G. \& Sıaudt, J. Neuroendocrinology 3, 136 (1968)

3. Bubenik, G.A.\& Brown, G.M. Experientia 29,619(1973).

4. Raisman, G. \& Field, P.M. Brain Res. 54, 1 (1973).

5. Nottebohm, F. \& Arnold, A.P. Science 194,211 (1976).

6. Gurney, M.E. \& Konishi, M. Science 208, 1380 (1980).

Greenough, W.T., Carter, C.S., Steerman, C.\& DeVoogd, T. Brain Res. 126, 63 (1977).

8. Gorski, R.A., Gordon, J.H., Shryne, J.E. \& Southam, A.M. Brain Res. 148, 333 (1978).

9. Rethelyi, M. Neuroendocrinology 28, 82 (1979).

10. Matsumoto, A. \& Arai, Y. Brain Res. 190, 238 (1980)

10. Matsumoto, A. \& Arai, Y. Brain Res. 190, 238 (1980).
11. Breedlove, S.M. \& Arnold, A.P. Science 210, 564 (1980).

11. Breedlove, S.M. \& Arnold, A.P. Science 210, 564 (
12. Loy, R. \& Milner, T.A. Science 208, 1281 (1980).

13. Toran-Allerand, C.D. Brain Res. 106, 407 (1976).

4. Toran-Allerand, C.D., Gerlach, J.L. \& McEwen, B.S. Bra in Res. 184, 517 (1980).

15. Lund, R.D. Development and Plasticity of the Brain (Oxford University Press, New York, 1978).

16. McLennan, I.S., Hill, C.E. \& Hendry, I.A. Nature 283, 206 (1980).

17. Jonakait, G.M., Bohn, M.C. \& Black, I.B. Science 210. 551 (1980).

18. MacLusky, N.J., Lieberburg, I. \& McEwen, B.S. Brain Res. 178,129 (1979).

19. Vito, C.V.\& Fox, T.O. Science 204, 517 (1979).

20. Vito, C.C., Wicland, S.J. \& Fox, T.O. Nature 282, 308 (1979).

21. Lieberburg, I., MacLusky, N.J. \& McEwen, B.S. Brain Res. 196, 125 (1980).

22. Reddy, V.V.R., Naftolin, F. \& Ryan, K.J. Endocrinology

94, 117 (1974).
23. Denef, C., Magnus, C. \& McEwen, B.S. Endocrinology 94, 1265 (1974).

24. Goy, R.W. \& McEwen, B.S. (eds) Sexual Differentiation of the Brain (MIT Press, Cambridge, 1980).

25. Baum, M.J. Neurosci. Biobehav. Rev. 3, 265 (1979).

26. Ifft, J.D. J. comp. Neurol. 144, 193 (1972).

27. Attardi, B. \& Ohno, S. Endocrinology 99, 1279 (1976).

8. Weiss, J. \& Ward, I.L. Endocrinology 106, 306 (1980).

29. Westley, B.R. \& Salaman, D.F. Nature 262, 407 (1976).

30. Lieberburg, 1., Krey, L.C. \& McEwen, B.S. Brain Res 178, 207 (1979). 